\title{
Viral and Transgenic Reporters and Genetic Analysis of Adult Neurogenesis
}

\author{
Grigori Enikolopov ${ }^{1}$, Linda Overstreet-Wadiche ${ }^{2}$, and Shaoyu $\mathrm{Ge}^{3}$ \\ ${ }^{1}$ Cold Spring Harbor Laboratory, Cold Spring Harbor, New York 11724 \\ ${ }^{2}$ Department of Neurobiology, University of Alabama at Birmingham, Birmingham, Alabama 35294 \\ ${ }^{3}$ Department of Neurobiology and Behavior, Stony Brook University, Stony Brook, New York 11794 \\ Correspondence: enikolop@cshl.edu
}

Stem and progenitor cells of the developing and adult brain can be effectively identified and manipulated using reporter genes, introduced into transgenic reporter mouse lines or recombinant viruses. Such reporters rely on an ever-increasing variety of fluorescent proteins and a continuously expanding list of regulatory elements and of mouse lines engineered for cell- or time-specific recombination. An important extension of stem-cell-based genetic strategies is an opportunity to explore the properties of newly generated neurons and their contribution to synaptic plasticity. Here, we review available strategies for marking and quantifying various classes of stem and progenitor cells in the adult brain, genetically tracing their progeny, and studying the properties of stem cells and new neurons. We compare various experimental approaches to labeling and investigating stem cells and their progeny and discuss caveats and limitations inherent to each approach.

In adult humans and animals, neural stem cells maintained at specific locations in the adult brain, can produce new neurons that integrate into the existing neural circuits and contribute to neural plasticity. Neural stem cells are the only proven source of new neurons in the adult brain; therefore, our understanding of the features and the role of newly generated neurons depends on the ability to identify adult stem cells, trace their lineage, and reveal basic mechanisms governing their maintenance, division, differentiation, and death.

There are various strategies to visualize, identify, and enumerate stem cells and their progeny in the adult brain in vivo. Traditionally, studies of neurogenesis relied on immunocytochemical staining of brain sections using stem-cell-specific antibodies and their combinations and on marking ("birth dating") dividing stem cells and their progeny using thymidine analogs. These techniques are now complemented by powerful genetic approaches for ontogenetic labeling: generation of transgenic reporter animals constitutively expressing marker proteins; indelible labeling of stem cells and their progeny using inducible (usually Cre-based) recombination; and viral delivery of marker genes to stem cells and their progeny. The general strategy for all genetic approaches to neurogenesis is to drive the expression of live

Editors: Fred H. Gage, Gerd Kempermann, and Hongjun Song

Additional Perspectives on Neurogenesis available at www.cshperspectives.org

Copyright (C) 2015 Cold Spring Harbor Laboratory Press; all rights reserved; doi: 10.1101/cshperspect.a018804

Cite this article as Cold Spring Harb Perspect Biol 2015;7:a018804 
G. Enikolopov et al.

markers, such as fluorescent proteins (FPs) of various color, maturation time, stability, or localization, in defined subclasses of stem cells and their progeny. This review will focus on these genetic approaches, describing available genetic tools and their applications for studying adult neurogenesis (with a bias toward hippocampal neurogenesis) and discussing their advantages and limitations. Interested readers can also consult other reviews in this series, including a review on detection and phenotypic characterization of adult neurogenesis (Kuhn et al. 2015).

\section{TRANSGENIC AND VIRAL STRATEGIES FOR IDENTIFICATION OF NEURAL STEM CELLS AND THEIR PROGENY}

Much of the current knowledge about adult neural stem cells and their immediate or distant progeny has been obtained through the use of constitutive transgenic mouse lines with genetically encoded markers. In such lines, a specific promoter, by directing expression of an FP, helps to identify cells, their subpopulations, or defined classes of their progeny. The range of such lines is steadily expanding, providing an abundant choice of reagents to probe adult stem cells. This general strategy is increasingly supplemented by the use of inducible transgenic mouse lines, in which Cre recombinase is activated by tamoxifen or doxycycline at a given time point to mark the progeny of the cells that have undergone recombination; again, a steadily growing collection of inducible lines facilitates the choice of genetic reagents. These two transgenic approaches, constitutive and inducible, are paralleled by the application of viral infection to label stem cells and/or their progeny. Delivery of viral vectors, usually based on adeno-associated viruses (AAVs), lentiviruses (LVs), and retroviruses (RVs) is increasingly taking advantage of the progress in generating transgenic mouse lines (for instance, by using regulatory elements validated in transgenics) and facilitates and accelerates analysis of adult neurogenesis. Viral-based approaches are further benefiting from efforts and progress in human gene therapy. In addition, all three ap- proaches rely on progress in generating new varieties of FPs.

\section{Constitutive Transgenic Reporter Lines}

The key to genetic reporter strategies is identifying regulatory elements that would reliably drive expression of the fluorescent marker in the cell subtype of choice. The most straightforward approach would be to express the marker under control of appropriate elements and apply standard approaches (pronuclear injection, bacterial artificial chromosomes (BACs), or knockin techniques) to generate transgenic mouse lines constitutively expressing the marker protein. Constitutive transgenic labeling is conceptually similar to immunohistochemical detection of cell subpopulations, identifying newly generated cells in a differentiation stagespecific manner. Numerous transgenic reporter mouse lines with constitutive expression of FPs became valuable instruments for visualizing stem and progenitor cells and adult-born neurons for studying their properties and for dissecting neuronal or astrocytic differentiation cascades into defined steps (reviewed by Dhaliwal and Lagace 2011); below, we highlight a few such lines that cover distinct developmental stages of neuronal birth and maturation.

\section{Inducible Reporter Lines}

Yet another set of valuable genetic tools for studying adult neurogenesis is presented by mouse lines carrying a fusion between Cre recombinase and a hormone-binding domain of the estrogen receptor, the latter mutated to have it respond to an exogenous (tamoxifen or its metabolite 4-hydroxy-tamoxifen) but not the natural ligand (Jensen and Dymecki 2014). When such a line (a driver) is crossed with a reporter line containing an FP gene whose expression is normally prevented by a STOP sequence flanked by the loxP recombination sites (a reporter line), injection of tamoxifen triggers recombination and FP accumulation in the competent cells. If such labeled cells self-renew or produce differentiated progeny, these derivatives will be also labeled by the FP (which is 
usually controlled by a strong constitutive promoter to maximize the chances of its expression in a widest range of cell types).

As with the constitutive reporters, there is a continuously expanding list of mouse lines with the chimeric recombinase expression controlled by regulatory elements active in neural stem/ progenitor cells or their progeny. These lines have been successfully used to visualize neurogenesis and to track the fate of a particular cell type, which was competent for tamoxifen-induced recombination at the time of induction (reviewed by Dhaliwal and Lagace 2011; Imayoshi et al. 2011; Sun et al. 2014). For instance, Nestin-CreER, Gli1-CreER, Glast1-CreER, and Sox32-CreER lines have been used to track the progeny of type 1 cells (stem cells), and doublecortin (DCX)-CreER lines have been used to track the progeny of type 2 cells (transiently amplifying progenitors). Furthermore, inducible recombination has been applied for clonal analysis of the stem-cell lineage and activity (Bonaguidi et al. 2011; Song et al. 2012; Jang et al. 2013; Merkle et al. 2014). Detailed mapping of the stem-cell differentiation cascade using inducible reporter lines complements the data obtained using constitutive reporters, potentially enabling the timing of the entire cascade and deduction of the fate of every subpopulation of stem and progenitor cells in the adult brain.

This review does not attempt to cover the rapidly growing field of genetic fate mapping for the adult neurogenic zones, but will mention several issues to consider when planning or interpreting such experiments. First, one has to remember that even when using the same regulatory elements to drive the expression of Cre recombinase, the resulting lines may not carry exactly the same features. For instance, several widely used Nestin-CreER driver lines show substantial variability in the specificity and efficiency of recombination induced in the bigenic combinations with a reporter line (Sun et al. 2014; G Enikolopov, unpubl.). Conversely, different reporter lines can show somewhat different results even when combined with the same driver line (G Enikolopov, unpubl.). Although this may not be important for the broad picture of fate choice, it may become critical when considering small populations or rare events in the neurogenic zones. Second, one should not expect full correspondence between the cells marked in the constitutive reporter lines and cells undergoing initial recombination in the inducible bigenic reporter lines. Third, one has to keep in mind that not only the progeny but the initial cells that have undergone recombination will become stained by the FP expression. Therefore, it may be important to compare various time points after induction to better distinguish the original recombined cells from their progeny. For instance, one may see type 1 , type 2, immature neurons, mature neurons, astrocytes, pericytes, and oligodendrocyte progenitors several weeks after tamoxifen induction in a bigenic strain containing a particular NestinCreER driver, but only some of these cells will correspond to the bona fide progeny of stem cells (i.e., some other labeled cell types could correspond to the "original" recombined cells that may not have produced any progeny). Finally, one has to consider that quantitative assessment of the progeny cell types (e.g., neurons vs. astrocytes) may greatly vary depending on the driver line, particularly if the driver covers overlapping but not identical populations (e.g., a line in which recombination is induced in both type 1 and type 2 cells may be interpreted as producing a higher proportion of neurons than a line, in which recombination is induced only in type 1 cells, even if the relation among these cell types is linear).

\section{Viral Labeling of Neural Stem Cells} and Their Progeny

An alternative to generating a transgenic reporter line is often provided by the availability of viral vectors to transduce stem and progenitor cells and their progeny. Viral gene delivery has been used extensively to transduce cells in a wide range of species, including humans, as an approach to gene therapy (Thomas et al. 2003; Cockrell and Kafri 2007). Different types of viral vectors, particularly AAV, LV, and RV based, have been designed for such delivery. Their use offers both shorter analysis time than regular trans- 
G. Enikolopov et al.

genic approaches and, often, greater flexibility, particularly when combined with transgenic lines with a defined expression range of the reporters they carry.

AAV is a DNAvirus in the Parvoviridae family with no known pathogenesis in humans (Smith 2008). These vectors normally express transgenes transiently, although there are suggestions that low levels $(<15 \%)$ of integration into the host genome can occur (McCarty et al. 2004). AAVs can carry transgenes up to $\sim 5 \mathrm{~kb}$ in length, although some reports state that DNA fragments up to $9 \mathrm{~kb}$ can be integrated (Allocca et al. 2008). Although specific serotypes of AAV usually infect defined populations of cells, they can infect both dividing and nondividing cells. This broad spectrum of infection capability, together with the inability to fully integrate into the host genome, limits the application of AAVs in labeling adult neural stem cells. However, specificity of the AAV-based reporters can be improved by using cell-type-specific promoters. Specificity can be further improved by relying on conditionally activated reporter expression; for instance, a loxP-flanked FP gene can be engineered to be active only in a specific subtype of cells by delivering the recombinant virus to the neurogenic zones of a transgenic animal expressing Cre recombinase under a specific promoter. Here, tissue or cell specificity is enforced by the possibility of a temporal control; for instance, by injecting a viral vector carrying a loxP-based green fluorescent protein (GFP) at a given time into a specific area of the brain of the Sox-Cre or Nestin-Cre transgenic animal.

Another type of viral vector used to transduce neural cells is based on the LV of the Retroviridae family. An important feature of LV is that it can carry fairly large insert sizes, up to $12 \mathrm{~kb}$. LVs integrate into the genome in a well-defined manner, which, especially when combined with Cre-Lox recombination or Tet expression systems, allows for high degree of temporal control (Carlen et al. 2009). The envelope protein of the viral particle determines both the cell type to be infected and the mechanism by which the virus gains entry to the cell. The most commonly used envelope protein is glycoprotein $\mathrm{G}$ from vesicular stomatitis virus
(VSVG). Because VSVG-pseudo-typed LVs infect all central nervous system (CNS) cell types, the specificity of these vectors is achieved by using specific promoters driving expression of the inserted reporter. With an appropriate promoter, these viruses can mark neural stem cells with level of specificity similar to those of regular transgenic approaches.

Although AAVs and LVs are efficient in infecting neuronal and glial cells in the nervous system, tracing and manipulating neural stem cells requires the virus to specifically target this population of dividing cells. In the past few decades, retroviral vectors, those derived from the Moloney murine leukemia virus (MMLV), for example, have been engineered to target dividing cells. During integration into an infected cell, the RV binds surface receptors located on the host cell's plasma membrane. After binding, the viral membrane, via its envelope protein, and the host cell membrane fuse with genetic material transmitted into the host cell. The retroviral genetic material is then replicated in the host cell by reverse transcriptase to produce DNA from the viral RNA genome. If the host cell enters division and, therefore, breaks down its nuclear membrane during mitosis, retroviral integrase becomes capable of inserting the viral DNA into the host genome. The genomic integration site depends on the virus subtype and shows a preference for loci with high transcriptional activity (Mitchell et al. 2004). After integration, the RV-based vector replicates as part of the host cell's DNA. Thereafter, the infected host cells and their progeny will carry the reporter transgene. Thus, RV vectors allow expression of one or multiple transgenes under the control of a particular promoter (e.g., cytosine-adenosine-guanine [CAG], glial fibrillary acidic protein [GFAP], Nestin, or DCX) specifically in dividing cells; therefore, when a population of labeled cells is later analyzed, it can be presumed that the precursor cell underwent division at or near the time of infection.

\section{Fluorescent Markers for Cell Labeling}

A key component of constitutive, inducible, or viral reporters is an FP driven by appropriate 
regulatory elements. The palette of FP expression in transgenic reporter lines is constantly increasing, with GFP, cyan fluorescent protein (CFP), DsRed, mCherry, and tdTomato routinely used. In addition, more advanced variants of FPs are continuously being generated and characterized for the purposes of genetic cell labeling. There is an ongoing effort to expand the range of available FPs with new excitation/emission features (with a particular emphasis on the far-red end of the spectrum in proteins, such as mKate), altered multimerization, stability, or solubility (Chudakov et al. 2010). A parallel effort focuses on generating FPs that are slowly maturing (such as dTimer), are photoactivatable (such as KikGR and Kaede), photoswitchable (such as Dendra) and reversibly switchable (such as Dronpa) (reviewed by Abe and Fujimori 2013; Shcherbakova et al. 2014). Although only a few of these proteins have been used to mark neural tissue, their application in other types of transgenic models (reviewed by Abe and Fujimori 2013) helps in selecting appropriate candidates (e.g., avoiding FP versions that may be detrimental or toxic to the cells and the animal).

An important point to consider is that even with the most selective and stringent regulatory elements expression of the FP marker does not exactly recapitulate expression of the endogenous gene from which these elements were derived. FPs may persist in cells longer than the corresponding protein; therefore, cells that would otherwise not be marked by conventional means (e.g., by immunocytochemical staining for that protein) would be highlighted using this approach. Conversely, FPs may also persist for a shorter time than the corresponding endogenous protein, therefore compressing the range of highlighted cell types. This should not necessarily be considered a disadvantage; for instance, an FP that remains in a progeny cell longer than the endogenous protein may provide an opportunity to visualize both the original cell and its progeny and infer the lineage relationships between them. The ability to dissociate the presence of the FP marker from that of the cognate protein is taken further in reporter lines expressing Fucci proteins, whose accu- mulation is controlled by the phase of the cell cycle (Abe et al. 2013).

\section{USING REPORTER LINES TO DISSECT NEURONAL DIFFERENTIATION CASCADE}

The constantly growing list of available constitutive reporter mouse lines allows investigators to apply the most appropriate transgenic model to the question at hand. These lines use various regulatory elements and FPs of different color and subcellular localization to provide access to virtually any subclass of stem, progenitor, and differentiated cells in the adult brain.

Historically, much information has been derived from lines expressing FPs under the control of the regulatory elements derived from the gene encoding the stem-cell marker nestin. Crucial among these elements is a powerful enhancer located in the second intron of the gene, which can direct expression of a chosen marker to neuroepithelial and neural stem cells of the embryo and adult animal (Zimmerman et al. 1994). This enhancer has been used in combination with various other regulatory elements to generate Nestin-GFP reporter lines (Yamaguchi et al. 2000; Kawaguchi et al. 2001; Mignone et al. 2004) and later derivatives (Encinas et al. 2006; Encinas and Enikolopov 2008). Several lines of evidence show that FP-positive cells in these Nestin-based transgenic lines accurately represent neural stem and early progenitor cells in the developing and adult nervous system and cover the vast majority of such cells (Kronenberg et al. 2003; Kempermann et al. 2004; Mignone et al. 2004; Encinas et al. 2006, 2011b; Encinas and Enikolopov 2008). Nestin-based reporter lines continue to be generated and a researcher can now choose among multiple lines that differ in the color of the FP, its fluorescence intensity, or its subcellular localization. For instance, a series of mouse lines has been generated that uses the same vector backbone containing the promoter and enhancer of the rat Nestin gene to drive expression of GFP, mCherry, CFP with nuclear localization (CFPnuc), or H2B-GFP (the latter two with nuclear localization of the signal) (Mignone et al. 2004; Encinas et al. 2006; Encinas and Enikolopov 2008). Moreover, even the 
G. Enikolopov et al.

basic Nestin-GFP-expressing lines are available in different variations (e.g., using different promoters in addition to an obligatory enhancer) (Yamaguchi et al. 2000; Kawaguchi et al. 2001; Mignone et al. 2004). Although the basic pattern of the transgene expression is similar in all of these lines, such variations may become important when particular subpopulations of stem and progenitor cells are followed or characterized in more detail.

To illustrate the application of constitutive Nestin-based reporter lines for studying adult neurogenesis, consider three FP lines that use exactly the same promoter and enhancer elements derived from the rat Nestin gene (Fig. 1). In Nestin-GFP mice (Mignone et al. 2004), the fluorescent signal highlights all of the soma and the processes of stem and early progenitor cells (Fig. 1A) and these mice are well suited for the studies of the distribution and morphology of neuronal precursors in the developing and adult brain. In Nestin-CFPnuc mice (Encinas et al. 2006) the signal is localized in the cell nucleus and the distribution of the stem and progenitor cells is visualized as a punctuate pattern. This nuclear representation of stem and progenitor cells greatly reduces the complexity of their distribution pattern and permits their unambiguous enumeration by means of confocal stereology (Fig. 1B). Moreover, Nestin-GFP and Nestin-CFPnuc lines can be crossed to efficiently visualize both the soma and the nuclei of stem and progenitor cells (Fig. 1C). In Nestin-mCherry animals (Ding et al. 2012; G Enikolopov, unpubl.), stem and progenitor cells are marked by red fluorescence; this becomes important for generating multiallelic reporter lines, in which an FP of a different color marks the progeny of stem cells (e.g., NestinmCherry/Nestin-Cre-ER/ZEG mice) or other types of stem cells (e.g., Nestin-mCherry/ Sox2-GFP mice). Together, this set of matching lines expands the palette of available colors and the range of possible experiments.

Remarkably, in these lines, expression of FPs also marks stem/progenitor cells in a range of nonneural tissues-anterior pituitary, ovaries, bone marrow, hair follicles, skeletal muscle, testis, and liver among them (Davidoff et al. 2004;
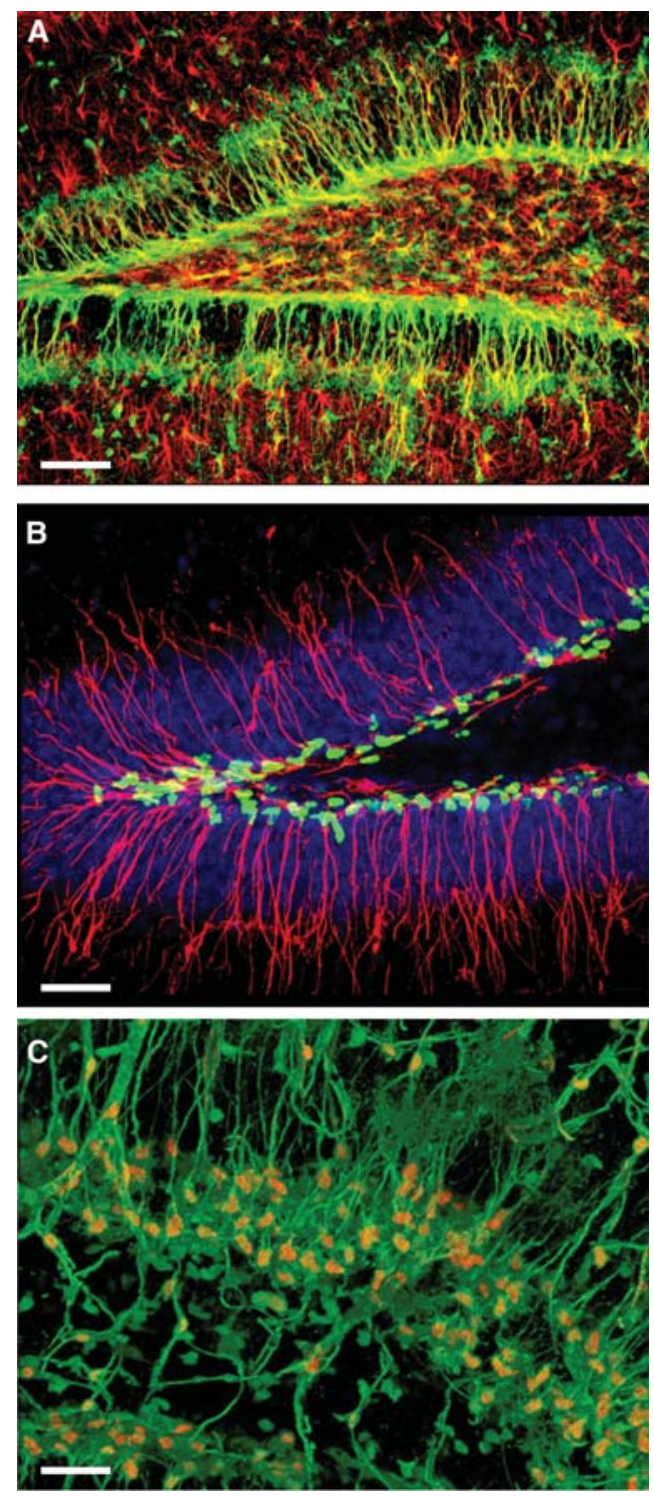

Figure 1. Neural stem and progenitor cells are visualized in Nestin-fluorescent protein (FP) reporter mice. (A) Neural stem cell and progenitor cells (green) in the dentate gyrus (DG) of Nestin-green fluorescent protein (GFP) mice (glial fibrillary acidic protein [GFAP] staining for astrocytes, red). (B) Nuclei of neural stem cell and progenitor cells (green) in the DG of Nestin-CFPnuc mice (Nestin staining of radial processes, red; DAPI staining of the cell nuclei, blue). (C) Nuclei (orange) and soma of neural stem cell and progenitor cells (green) in the DG of the Nestin-GFP/Nestin-CFPnuc hybrid mice (images courtesy of JM Encinas, A-S Chiang, and G Enikolopov). Scale bars, $50 \mu \mathrm{m}(A) ; 40 \mu \mathrm{m}(B) ; 30 \mu \mathrm{m}(C)$. 
Gleiberman et al. 2005, 2008; Day et al. 2007; Mignone et al. 2007; Mendez-Ferrer et al. 2010; Flesken-Nikitin et al. 2013). This provides an ability to identify and analyze stem cells in these tissues in the same animal, thus facilitating the experimental design for multiplex monitoring changes in the stem-cell compartments of different tissues.

For the adult hippocampus, the use of Nestin-based reporter lines allows one to define classes of precursors in the dentate gyrus (DG) based on the morphology of the labeled cells, the marker proteins that they express, and their mitotic activity. Several main classes of cells in the neuronal lineage in the DG can be identified and visualized by reporter transgenes; these classes encompass and partially overlap the categories of neuronal precursors defined by other approaches. The main stem-cell class is represented by radial glia-like GFAP/Nestin/vimentin/ brain lipid-binding protein (BLBP)/Sox2positive, Nestin-FP-expressing cells, whose soma resides in the subgranular cell zone (SGZ). These cells have been defined as type 1 cells (Kronenberg et al. 2003; Kempermann et al. 2004), GFP-bright cells (Mignone et al. 2004), retinoic acid (RA) cells (Seri et al. 2004), and quiescent neural progenitors (QNPs) (Encinas et al. 2011b). FPs continue to be expressed in progeny of these radial glia-like stem cells. Such cells still reside in the SGZ but lack the radial processes (type 2 cells) (Kronenberg et al. 2003; Kempermann et al. 2004); these cells have also been described as GFP-dim cells (Mignone et al. 2004) and amplifying neural progenitors (ANPs) (Encinas et al. 2006, 2011b). The FP signal in Nestin-based lines gradually disappears as progenitors exit the cell cycle. Further classes of precursors are represented by postmitotic neuroblasts that cease to express FP markers, by immature neurons that express neuronal markers and whose morphology gradually changes to that of mature granule cells (GCs), and by mature differentiated GC neurons with developed apical dendrites and axons forming the mossy fiber. These neuronally differentiating cells can be identified and studied using other reporter lines, in which FP expression is driven by the promoters of the DCX, proopiomelanocortin (POMC), or GAD67 genes as described in the following section. Thus, the use of reporter mice enables efficient dissection of the neuronal differentiation cascade in the DG into distinct steps and assembly of a detailed scheme of entire cascade (Encinas et al. 2006, 2011b; Encinas and Enikolopov 2008). As a following step, this scheme can be used to determine the classes of stem and progenitor cells in the DG that are affected by various pro- and antineurogenic factors and stimuli (for examples of such analyses, see Encinas et al. 2006, 2011a; Park et al. 2013).

The use of reporter mice also enabled our studies (G.E.), which indicate a new model for the quiescence, maintenance, and division of the adult hippocampal stem cells. Our results show that adult neural stem cells may remain quiescent for their entire postnatal life, but, when activated, rapidly divide several times in quick succession to bud off daughter cells that eventually yield neurons, whereas the remaining stem cell differentiates into a mature astrocyte, thus leaving the stem-cell pool. Hence, most hippocampal stem cells can be described as a "single-use" or a "disposable" unit-used in adulthood only once and then abandoned in its stem-cell capacity. We also found that astrocytic differentiation of hippocampal stem cells is tightly coupled to their division, that all dividing stem cells of the hippocampus convert into astrocytes, and that new astrocytes of the DG derive from these stem cells. Thus, targeted application of Nestin-based reporter lines suggests a new basic mechanism of neural stem cell disappearance in the aging hippocampus - their division-coupled astrocytic differentiation (Encinas et al. 2011b).

The application of Nestin-based reporter lines described above is provided merely as a guide. The same approach can be used to further define the subpopulations of stem cells and study their properties. For instance, adult radial glia-like stem cells are successfully visualized in lines that use regulatory elements of Gli1, GFAP, GLAST, BLBP, Prominin, Ascl1, Hes5, or Sox2 genes to drive expression of FPs (Nolte et al. 2001; Liu et al. 2006; Steiner et al. 2006; Suh et al. 2007; Lugert et al. 2010; Bonaguidi et al. 


\section{G. Enikolopov et al.}

2011; Encinas et al. 2011b; Kim et al. 2011; DeCarolis et al. 2013), and the challenge is to use these lines to define various phases of the stemcell life cycle. In conclusion, an expanding range of available reporter lines offers an ample genetic toolbox to cover (essentially, to "tile") the entire differentiation cascade leading from stem cells to new neurons and astrocytes (Fig. 2), and to study the features of distinct steps of the cascade.

\section{USING REPORTER LINES TO DEFINE MATURATION OF NEW NEURONS}

Here, as a guide, we describe several lines that have been particularly useful for dissecting the process of maturation of newborn neurons in the DG.

\section{Nestin-Based Transgenic Lines}

In addition to investigations of stem-cell division and differentiation, Nestin-GFP mice have also been used to study the physiological properties of neural precursors and the signaling mechanisms involved in their maturation. Early studies show that acute hippocampal slices of Nestin-GFP mice GFP-expressing cells, which fall into two classes based on morphology, also show different intrinsic membrane properties (Filippov et al. 2003; Fukuda et al. 2003). The larger type 1 cells with radial processes have passive membrane properties and low input resistance typical of astrocytes, whereas the smaller type 2 cells have higher input resistance and some voltage-gated currents. Type 1 cells are reported to show tonic $\gamma$-aminobutyric acid $\left(\mathrm{GABA}_{\mathrm{A}}\right)$ receptor-mediated currents (Song et al. 2012; but see Tozuka et al. 2005), whereas some type 2 cells also receive synaptic GABAergic currents (Tozuka et al. 2005; Wang et al. 2005; Song et al. 2013). Based on the identification of GABAergic signaling to progenitors and immature neurons, many subsequent studies have illustrated specific mechanisms contributing to GABA-mediated regulation of adult neurogenesis (Dieni et al. 2012).

\section{DCX-Based Transgenic Lines}

DCX is a microtubule-associated protein critically involved in neuronal migration and neurite outgrowth that is widely used as a marker for phenotypic identification of neuronal precursors and immature neurons. DCX is not ex-

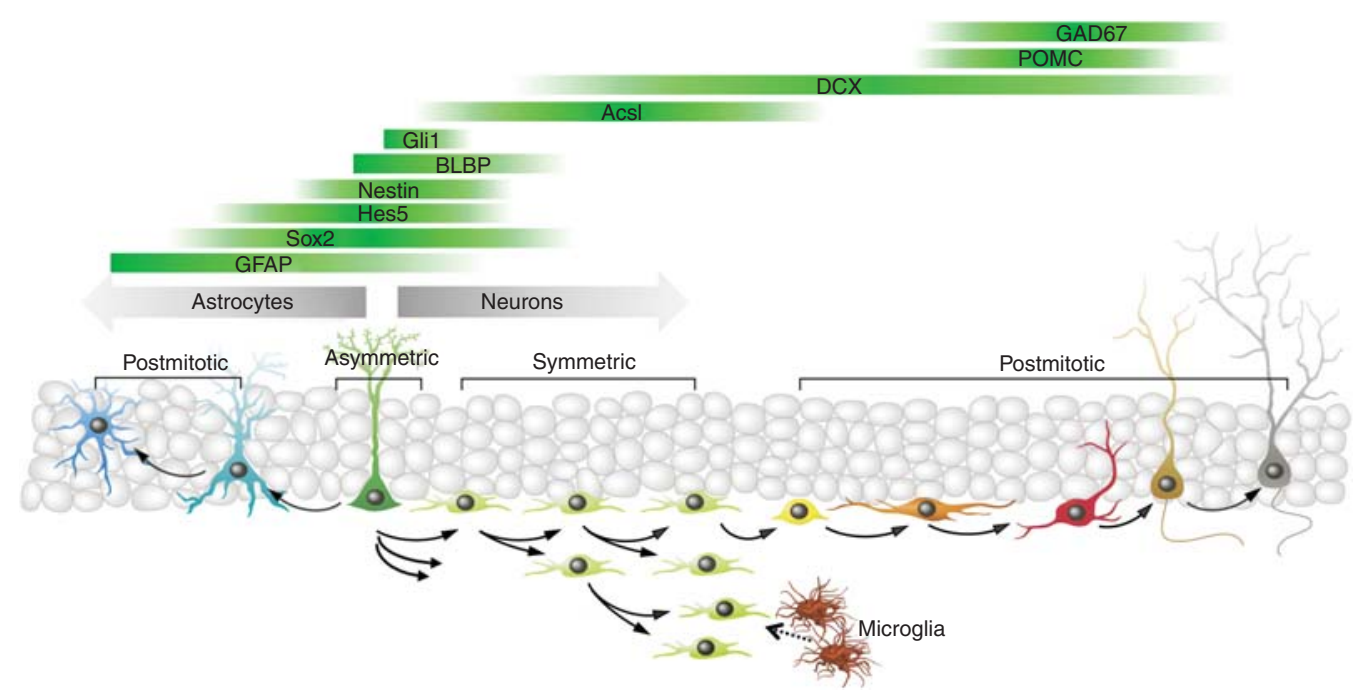

Figure 2. Schematic summary of the neuronal and astrocytic differentiation cascades in the dentate gyrus (DG) as reflected in transgenic reporter mouse lines. POMC, Proopiomelanocortin; DCX, doublecortin; BLBP, brain lipid-binding protein; GFAP, glial fibrillary acidic protein. (From data in Encinas et al. 2011b; modified, with permission, from the authors.) 
pressed exclusively in newborn cells, as it can be reexpressed in certain populations of mature neurons that are undergoing structural plasticity (Nacher et al. 2001). However, in the DG and olfactory system, it is reliably expressed in neuronal precursors and newborn neurons (Brown et al. 2003; Couillard-Despres et al. 2005). Couillard-Despres and colleagues (2006) generated transgenic mice using the identified $3.5-\mathrm{kb}$ fragment upstream of the DCX ATG start codon to drive expression of GFP or DsRed. Labeled cells have a variety of immature morphologies, consistent with the range of developmental stages that are characterized by DCX expression. DCX-based transgenic reporters have been used to examine immature cells in aged mice and to isolate immature neurons for gene-expression profiling (Couillard-Despres et al. 2006; Bracko et al. 2012). Recent work has also characterized the electrophysiological properties of a similar line of DCX-enhanced green fluorescent protein (EGFP) mice developed by the Gene Expression Nervous System Atlas BAC transgenic project (GENSAT) (Spampanato et al. 2012).

Transgenic mice expressing inducible recombinase under control of the DCX promoter are useful for selectively identifying and manipulating new neuron maturation, because this approach avoids Cre expression in stem-cell populations that continually produce additional cohorts of new neurons (Jablonska et al. 2010; Zhang et al. 2010; Cheng et al. 2011). One unique feature of two of these DCX-CreER lines is that they enable selective manipulation of either SGZ or subventricular zone (SVZ) neurogenesis, because each line expresses the transgene in complementary neurogenic regions (Yang et al. 2011). Xiong and colleagues used the hippocampal-specific line to show that spine density on immature neurons undergoes biphasic growth, with a robust increase in spine density in the first weeks followed by a reduction in density over the next 2 mo suggestive of synaptic pruning (Cheng et al. 2011). Gallo and colleagues showed that DCX-expressing neuroblasts in the SVZ respond to demyelination of the corpus callosum by switching cell fate and migratory behavior to become oligodendrocytes that repopulate the demyelinated region
(Jablonska et al. 2010). Together, these inducible lines provide high spatial and temporal precision for examining and manipulating adultgenerated neurons.

\section{POMC-EGFP Reporter Mice}

Transgenic mice with EGFP expressed under the control of regulatory sequences in the POMC gene labels postmitotic newborn GC (Overstreet et al. 2004). DG expression requires cryptic promoter sequences distinct from those required for expression in POMC-producing cells of the pituitary and POMC expression is undetectable, indicating that POMC-EGFP in the DG is unrelated to expression of the POMC gene product. Characterization of hippocampal FP expression in the POMC-EGFP mouse reveals that labeled cells have a generally homogenous morphology consisting of small cell bodies located near the SGZ and a primary dendrite that branches within the inner molecular layer (Fig. 3A) (Overstreet et al. 2004). FP-labeled cells have membrane properties consistent with immature neurons, including a very high infrared (IR), averaging $~ 9$ GOhm in perforated patch recordings (Overstreet-Wadiche et al. 2005). Colabeling with BrdU is detected between 3 and $24 \mathrm{~d}$ after BrdU administration, with the peak of colabeling at 10 to $12 \mathrm{~d}$ (Overstreet-Wadiche et al. 2006). At this developmental stage, GABAergic synapses are the primary source of synaptic input, whereas excitatory glutamatergic synapses are just beginning to form (Markwardt et al. 2009, 2011; Chancey et al. 2013, 2014). Thus, POMC-EGFP mice allow identification of an early developmental stage at the onset of synaptic integration. This stage is achieved by newborn GCs in the first $3 \mathrm{wk}$ following exit from cell cycle, with an average time of just under 2 wk. POMC-Cre transgenic mice have also proven useful for manipulating gene expression in postmitotic dentate GCs (McHugh et al. 2007; Nakashiba et al. 2012).

The uniform membrane properties and morphology of POMC-EGFP-labeled cells suggest that they constitute a relatively brief developmental stage with a temporal window of FP expression that is shorter than that seen in DCX 
G. Enikolopov et al.
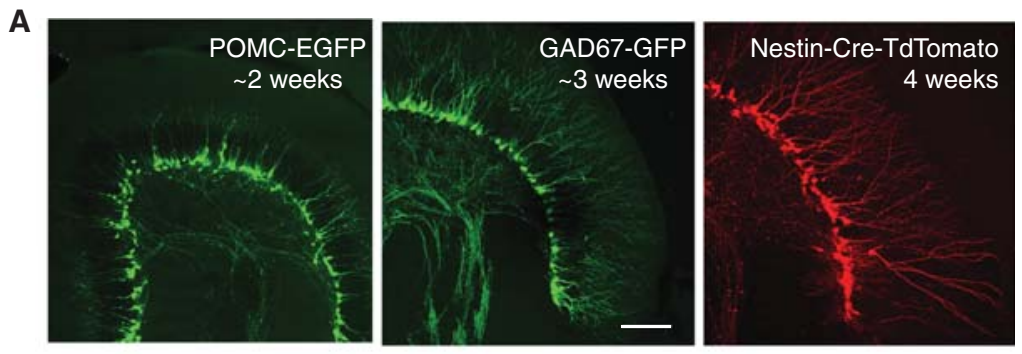

B
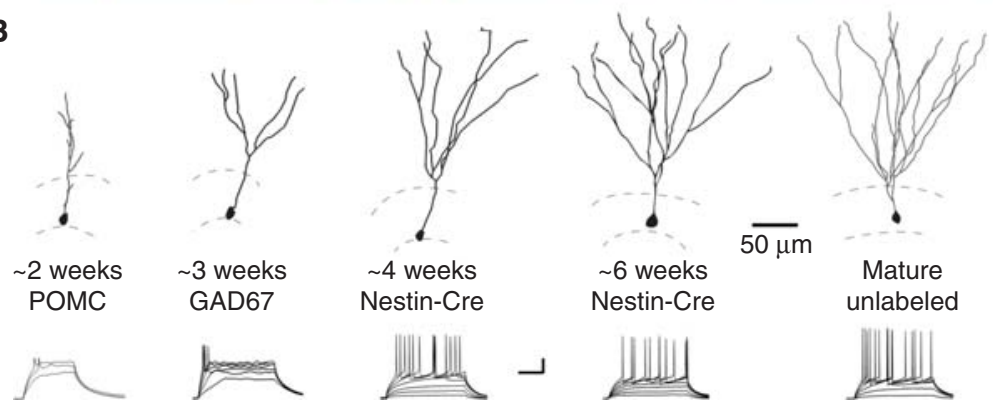

Figure 3. Studying neural maturation with transgenic reporter mice. $(A)$ Confocal images from reporter mice that identify progressive maturational stages of adult-born neurons. Proopiomelanocortin (POMC)-enhanced green fluorescent protein (EGFP) labels cells that are just under $2 \mathrm{wk}$ of age (Overstreet-Wadiche et al. 2006). GAD67-green fluorescent protein (GFP) labels cells are at 1 to $3 \mathrm{wk}$ (Zhao et al. 2010). Nestin-CreER ${ }^{\mathrm{T} 2} / \mathrm{Ail}_{4}$ labeling allows identification at any stage after tamoxifen-induced recombination (Lagace et al. 2007). Scale bar, $100 \mu \mathrm{m}$. (B) (Top) Reconstructed, labeled neurons from the indicated reporter mice illustrate the progressive maturation of granule cell morphology. (Bottom) Examples of voltage responses to current injections illustrate the maturation of intrinsic excitability. Scale bars, $20 \mathrm{mV}(A) ; 100 \mathrm{~ms}(B)$. (From Dieni et al. 2013; modified, with permission, from the authors.)

and GAD67 transgenics. Although they typically lack dendritic spines and functional glutamatergic input (Overstreet et al. 2004), a fraction of POMC-GFP-labeled cells have glutamatergic transmission mediated by $N$-methylD-aspartate (NMDA) receptor-only "silent" synapses (Chancey et al. 2013). The presence of silent synapses along with the lack of AMPA receptor (AMPAR)-containing synapses and the depolarized reversal potential for GABA-activated currents (Overstreet-Wadiche et al. 2005) make POMC-GFP-labeled newborn GCs a valuable tool for studying the role of GABA depolarization in activity-dependent synaptogenesis ("synapse unsilencing"). We found that GABA depolarization is necessary for activity-induced synapse unsilencing at the first nascent synapses on adult born neurons, both in vitro and in response to brief exposure of adult mice to an enriched environment (Chancey et al. 2013).
Furthermore, pharmacological and optogenetic approaches reveal that the first glutamatergic synapses arise from hilar mossy cells that make up the associational/commissural pathway rather than from the performant path that originates in the entorhinal cortex (Kumamoto et al. 2012; Chancey et al. 2014). Because the rate of GC maturation is not homogeneous and subject to regional and activity-dependent modulation (Overstreet-Wadiche et al. 2006; Piatti et al. 2011; Snyder et al. 2012), the ability to identify adult-born neurons at a homogeneous functional stage is useful for identifying mechanisms of synaptogenesis that persist for only a brief period during GC maturation.

\section{GAD67 Reporter Mice}

GAD67, one of the synthetic enzymes for GABA production, is typically associated with 
GABAergic interneurons. But, recently, BAC transgenic mice expressing GFP under the control of GAD67 regulatory elements revealed robust expression in immature dentate GC (Zhao et al. 2010). Similar to many other GAD67based reporter lines, GABAergic interneurons in other brain regions express GFP, but in this line hippocampal interneurons are unlabeled. Interestingly, the transient expression of GFP in immature GCs appears to result from the low level of GAD67 expressed in developing GC mossy fibers (Sandler and Smith 1991; Sloviter et al. 1996; Zhao et al. 2010). GAD67-labeled GCs share several features with POMClabeled GCs, including overlap with immature markers like DCX and PSA-NCAM, as well as immature morphology. However, GAD67-labeled cells also have sparsely spiny dendrites that extend through the molecular layer, and they display a range of synaptic and electrophysiological properties. GAD67-labeled immature GCs are highly colabeled with BrdU between 7 and $21 \mathrm{~d}$ after BrdU administration, suggesting they overlap with the early developmental stage identified in POMC-GFP transgenics but also label new GCs at a more mature stage (Zhao et al. 2010). The intrinsic and synaptic properties of immature GCs in another line of GAD67GFP mice have also been well characterized (Cabezas et al. 2013). Although the functional role of GABA synthesis in immature GCs remains controversial (Uchigashima et al. 2007), recent work using GAD67-GFP transgenic mice showed that GABA release from immature mossy fibers can modulate mossy fiber excitability via $\mathrm{GABA}_{\mathrm{B}}$ autoreceptors (Cabezas et al. 2012).

\section{Inducible Reporter Lines}

We (L.O.-W.) recently characterized the maturation of intrinsic and synaptic electrophysiological properties of immature GCs using NestinCreER $^{\mathrm{T} 2}$ mice (Lagace et al. 2007; Decarolis et al. 2013) crossed with R26R-TdTomato reporter mice (Dieni et al. 2013). Similar to retroviral labeling, inducible transgenic systems based on promoters selective for stem cells or progenitors allow identification of neural progeny at any de- sired time interval after recombination is initiated. The time resolution of birth dating using Nestin-based inducible reporters is restricted by continual production from the population of Nestin-expressing stem cells, that is, the interval after tamoxifen induction will determine only the oldest postmitotic age of labeled GC. But, because the morphology of labeled cells is visible in acute slices, targeting recording based on cell morphology can select for functional stages. For example, selecting GCs with the most mature dendritic structure at each interval posttamoxifen injection resulted in a similar time course for the maturation of action potential properties as reported in prior retroviral labeling studies (Fig. 3B). In conclusion, all stages of adult neuronal development can be targeted for electrophysiological analysis using the wide variety of currently available mouse lines, including POMC-GFP, GAD67-GFP, and inducible Nestin-Cre and DCX-Cre.

\section{USING RETROVIRUS VECTORS FOR LINEAGE TRACING IN THE ADULT BRAIN}

Constitutive and inducible transgenic lines have become valuable tools for studying adult neurogenesis. However, a number of limitations inherent to these approaches remain. For instance, in many cases, the FP intensity is insufficient for a detailed in vivo analysis of stem cells or their progeny. In addition, in transgenic animals, it is often difficult to birth date labeled cells. Furthermore, in some cases, transgenic reporter lines may be poorly suited for the clonal analysis of individual stem cells. As an example, although it is possible to sparsely label neural precursors and trace their lineages in the DG of Nestin-CreER-based reporter mice, the generation time of the labeled lineage is difficult to trace and the resulting fluorescent signal is not always bright enough for in vivo experiments.

Some of these limitations can be overcome using retroviral labeling of the dividing cells in the adult brain. Stereotaxic injection of a retroviral vector carrying an FP into the neurogenic zones will allow some of these cells to be infected as they undergo mitosis and will result in progeny expressing the FP. Given the short life- 
G. Enikolopov et al.

span of RVs in vivo, one viral bolus will label only a small population of neurons that were born within a short time period since the injection. The development of newborn neurons can, therefore, be investigated at any time after retroviral injection to observe cells of different ages and at different stages of differentiation.

A typical experiment for single-cell analysis of a desired developmental process in vivo often uses an RV carrying an FP gene and a strong promoter element. When this approach is applied to the DG, a high level of FP expression in newborn granule neurons makes their clear visualization possible, with robust labeling of their dendrites and axons. Newborn cells and their organelles are usually visible within a few days following injection, and dendritic spines can be traced from the earliest stages of development. Whole-cell recordings from newborn neurons at different developmental stages enable the study of properties unique to newborn cells, such as the process of synaptic integration into existing neural circuits during maturation. Marker expression in fine neuronal substructures, such as thin dentate GC axons and small dendritic spines, depends on the quality and titer of the virus, the promoter used, and the time elapsed from the infection step. In the past decade, retroviral labeling has been successfully used to dissect the process of neuronal development and reveal some of its underlying mechanisms. For instance, the method was instrumental for demonstrating that adult-born dentate
GC first receive GABAergic inputs, followed, after $2 \mathrm{wk}$, by glutamatergic innervation (Ge et al. 2006, 2007). Similarly, retroviral labeling has been successfully used for tracing the synaptic integration of new neurons in the olfactory bulb (Ming and Song 2011).

\section{ADVANTAGES AND LIMITATIONS OF THE TRANSGENIC AND VIRAL SYSTEM FOR STUDYING ADULT NEUROGENESIS}

Constitutive and inducible reporter lines and viral systems to a large degree complement each other for the purposes of genetic, molecular, and physiologic analysis of adult neurogenesis. Table 1 illustrates the strength and weakness of the available and to-be-developed (shaded) methods for ontogenetic cell labeling.

Transgenic reporter lines with genetically encoded markers have several advantages when identifying and monitoring newborn neurons and their precursors. Similar to retroviral labeling, transgenic labeling allows full morphological analysis of labeled cells in fixed and in live preparations, with the additional advantage that quantitative analysis can be performed because, unlike retroviral labeling, expression of the marker is independent of injection parameters, such as injection site or the viral titer. Additionally, transgenic reporter lines with nuclear FPs can be used for precise quantitation of subtle changes in the size of particular populations of cells. Transgenic systems are also

Table 1. The strength and weakness of the available and to-be-developed (shaded) methods for ontogenetic cell labeling

\begin{tabular}{|c|c|c|c|c|c|c|}
\hline & $\begin{array}{l}\text { Labeling } \\
\text { suitability }\end{array}$ & $\begin{array}{l}\text { Birth } \\
\text { dating }\end{array}$ & $\begin{array}{l}\text { Marker } \\
\text { level }\end{array}$ & Quantitation & $\begin{array}{c}\text { Gene } \\
\text { delivery }\end{array}$ & $\begin{array}{l}\text { Physiology } \\
\text { tests }\end{array}$ \\
\hline $\begin{array}{l}\text { Constitutive reporter } \\
\text { animals }\end{array}$ & Good, dense & Limited & $\begin{array}{l}\text { Poor to } \\
\text { good }\end{array}$ & Good & Good & $\begin{array}{l}\text { Limited to } \\
\text { good }\end{array}$ \\
\hline $\begin{array}{l}\text { CreER and Cre reporter } \\
\text { animals }\end{array}$ & $\begin{array}{l}\text { Subdose inducers, good, } \\
\text { sparse }\end{array}$ & Limited & $\begin{array}{r}\text { Poor to } \\
\text { good }\end{array}$ & Poor & Limited & Limited \\
\hline \multirow{2}{*}{$\begin{array}{l}\text { Retroviral labeling } \\
\quad \text { (Low titer) }\end{array}$} & Embryo cortex, good & Good & Fair & Poor & Limited & Good \\
\hline & Adult brain, poor & Good & Poor & Poor & Limited & Limited \\
\hline $\begin{array}{l}\text { Retroviral Cre }+ \text { Cre } \\
\text { reporter animals }\end{array}$ & Low titer, good, sparse & Good & Poor & Limited & Limited & Limited \\
\hline $\begin{array}{l}\text { Viral Cre }+ \text { Cre } \\
\text { reporter retrovirus }\end{array}$ & High titer, good, sparse & Good & Good & Limited & Good & Good \\
\hline
\end{tabular}


noninvasive, thus there are no potential confounding factors resulting from inflammation and injury at the injection site. Furthermore, transgenic animals can be subjected to behavioral analysis. Finally, reporter mice can be easily crossed with other genetically modified mice to examine the role of specific genes or mutations in adult neurogenesis.

An important caveat to consider, however, is that constitutive transgenic systems generally use regulatory elements of genes that are transiently expressed in individual cells during specific stages of their development; because some developmentally regulated genes might be reexpressed in mature neurons that may be undergoing structural or functional changes, specificity of the transgene expression in newborn cells must be confirmed by other approaches. Furthermore, because transgenic labeling identifies cells based on their ability to express a stage-specific marker, constitutive transgenic reporter lines provide a snapshot of a population of cells at a particular developmental stage. In contrast, labeling using inducible transgenic lines, retroviral vectors, or thymidine analogues (e.g., BrdU), permanently marks cells generated at a specific time ("birth date"), allowing individual cells to be tracked over time. The interpretations of the two types of labeling (transgenic vs. retroviral or BrdU) are, thus, quite distinct and warrant careful consideration when choosing which approach to use when studying continually regenerating and maturing populations of newborn neurons and their precursors.

Among many advantages of the retroviral labeling is the ability to target dividing stem cells with high precision, good suitability for birth dating and clonal analysis, and high potential for the physiological analysis of the progeny. For instance, transgenic approaches have been applied with stage-specific promoters for lineage tracing, but different sets of stem cells in mammals have similar developmental trajectories and, as a result, lineage tracing and genetic manipulation using these methods may cover an amalgam of large populations of cells. In contrast, the viral approach uses stereotaxic to deliver RVs, resulting in local cell transduction. By combining a retroviral vector with a promot- er of interest, it becomes possible to increase the specificity of the marker expression and to target cells of a specific population or at a particular developmental stage. An added benefit of the viral approach is the short time course required for experiments.

RVs have been successfully used to mark and birthdate clonally related neurons in the developing cortex, but challenges remain for replicating this process in adult tissue. In the fully developed brain, retroviral labeling mostly marks single adult-born neurons (Suh et al. 2007). This sparse labeling may result from the fact that RVs infect dividing cells in the proliferative zone, in which transiently amplifying cells represent the largest population because most adult neural stem cells in vivo are quiescent (Doetsch et al. 1999; Kronenberg et al. 2003; Bonaguidi et al. 2011; Encinas et al. 2011b). Thus, the vast majority of targets for viral infection in the adult DG are transiently amplifying progenitors. This limitation restricts many aspects of lineage study of hippocampal neural stem cells using the retroviral method.

One possible solution to overcome this limitation is to develop a virus-based labeling method to specifically target active radial glialike progenitors in the DG. For instance, because the GFAP promoter is active in most hippocampal neural stem cells but promptly turns off in the intermediate progenitors, GFAP-Cre mouse lines or lentivirus with GFAP promoter are able to deliver the Cre recombinase into the stem-cell population. Therefore, these cells can be labeled by constructing a retrovirus with a Cre-dependent cassette carrying an FP gene or other genes of interest. Such combinatorial methods (infecting a transgenic animal with Cre-dependent reporter cassette with a Cre-carrying retrovirus or combining a Cre-carrying LV with a retrovirus carrying Cre-dependent reporter cassette) should allow labeling specific actively dividing stem and progenitor cell populations and their neuronal lineages.

Although the retroviral method has proven powerful in marking and manipulating transduced stem cells and their progeny, some restrictions remain. Viruses and their delivery are invasive and, thus, may introduce trauma and 
G. Enikolopov et al.

inflammation, confounding interpretation. In the past decade, technical advancements, such as purified high titer stocks of viruses and fine injection needles, have been introduced to minimize these unwanted effects. The relatively small number of cells transduced restricts the use of the retroviral method for most behavioral tests. Another common limitation of the viral method is the significant effect of the large insert size on the viral titer. Finally, transgene insertion can potentially disrupt endogenous gene function.

Overall, although retrovirus-based genetic labeling and manipulation has some limitations, it provides a powerful tool to visualize and genetically control neural stem cells and their progeny for studying their generation and development.

In conclusion, progress in transgenic and viral reporter systems for studying neurogenesis will be propelled by (1) an increased repertoire of fluorescent markers; (2) an ever-growing collection of available reporter animal lines; (3) the introduction of recombination systems other than Cre/loxP (e.g., Flp/FRT); (4) using tetracycline-dependent gene expression or recombination (e.g., using Tet-based activators) in the reporters and establishing binary or ternary setups that would exploit various inducible and conditional expression/recombination systems (e.g., pursuing intersectional genetics; Jensen and Dymecki 2014); (5) increased quantitative resolution of the analysis; and (6) creative combination of the available viral and transgenic techniques.

\section{REFERENCES}

${ }^{*}$ Reference is also in this collection.

Abe T, Fujimori T. 2013. Reporter mouse lines for fluorescence imaging. Dev Growth Differ 55: 390-405.

Abe T, Sakaue-Sawano A, Kiyonari H, Shioi G, Inoue K, Horiuchi T, Nakao K, Miyawaki A, Aizawa S, Fujimori T. 2013. Visualization of cell cycle in mouse embryos with Fucci2 reporter directed by Rosa26 promoter. Development 140: 237-246.

Allocca M, Doria M, Petrillo M, Colella P, Garcia-Hoyos M, Gibbs D, Kim SR, Maguire A, Rex TS, Di Vicino U, et al. 2008. Serotype-dependent packaging of large genes in adeno-associated viral vectors results in effective gene delivery in mice. J Clin Invest 118: 1955-1964.
Bonaguidi MA, Wheeler MA, Shapiro JS, Stadel RP, Sun GJ, Ming GL, Song H. 2011. In vivo clonal analysis reveals self-renewing and multipotent adult neural stem cell characteristics. Cell 145: 1142-1155.

Bracko O, Singer T, Aigner S, Knobloch M, Winner B, Ray J, Clemenson GD Jr, Suh H, Couillard-Despres S, Aigner L, et al. 2012. Gene expression profiling of neural stem cells and their neuronal progeny reveals IGF2 as a regulator of adult hippocampal neurogenesis. J Neurosci 32: 33763387.

Brown JP, Couillard-Despres S, Cooper-Kuhn CM, Winkler J, Aigner L, Kuhn HG. 2003. Transient expression of doublecortin during adult neurogenesis. J Comp Neurol 467: $1-10$.

Cabezas C, Irinopoulou T, Gauvain G, Poncer JC. 2012. Presynaptic but not postsynaptic GABA signaling at unitary mossy fiber synapses. J Neurosci 32: 11835-11840.

Cabezas C, Irinopoulou T, Cauli B, Poncer JC. 2013. Molecular and functional characterization of GAD67-expressing, newborn granule cells in mouse dentate gyrus. Front Neural Circuits 7: 60.

Carlen M, Meletis K, Goritz C, Darsalia V, Evergren E, Tanigaki K, Amendola M, Barnabe-Heider F, Yeung MS, Naldini L, et al. 2009. Forebrain ependymal cells are Notch-dependent and generate neuroblasts and astrocytes after stroke. Nat Neurosci 12: 259-267.

Chancey JH, Adlaf EW, Sapp MC, Pugh PC, Wadiche JI, Overstreet-Wadiche LS. 2013. GABA depolarization is required for experience-dependent synapse unsilencing in adult-born neurons. J Neurosci 33: 6614-6622.

Chancey JH, Poulsen DJ, Wadiche JI, Overstreet-Wadiche L. 2014. Hilar mossy cells provide the first glutamatergic synapses to adult-born dentate granule cells. J Neurosci 34: 2349-2354.

Cheng X, Li Y, Huang Y, Feng X, Feng G, Xiong ZQ. 2011. Pulse labeling and long-term tracing of newborn neurons in the adult subgranular zone. Cell Res 21: 338-349.

Chudakov DM, Matz MV, Lukyanov S, Lukyanov KA. 2010. Fluorescent proteins and their applications in imaging living cells and tissues. Physiol Rev 90: 1103-1163.

Cockrell AS, Kafri T. 2007. Gene delivery by lentivirus vectors. Mol Biotechnol 36: 184-204.

Couillard-Despres S, Winner B, Schaubeck S, Aigner R, Vroemen M, Weidner N, Bogdahn U, Winkler J, Kuhn HG, Aigner L. 2005. Doublecortin expression levels in adult brain reflect neurogenesis. Eur J Neurosci 21: 1-14.

Couillard-Despres S, Winner B, Karl C, Lindemann G, Schmid P, Aigner R, Laemke J, Bogdahn U, Winkler J, Bischofberger J, et al. 2006. Targeted transgene expression in neuronal precursors: Watching young neurons in the old brain. Eur J Neurosci 24: 1535-1545.

Davidoff MS, Middendorff R, Enikolopov G, Riethmacher D, Holstein AF, Muller D. 2004. Progenitor cells of the testosterone-producing Leydig cells revealed. J Cell Biol 167: 935-944.

Day K, Shefer G, Richardson JB, Enikolopov G, YablonkaReuveni Z. 2007. Nestin-GFP reporter expression defines the quiescent state of skeletal muscle satellite cells. Dev Biol 304: 246-259.

Decarolis NA, Mechanic M, Petrik D, Carlton A, Ables JL, Malhotra S, Bachoo R, Gotz M, Lagace DC, Eisch AJ. 
2013. In vivo contribution of nestin- and GLAST-lineage cells to adult hippocampal neurogenesis. Hippocampus 23: 708-719.

Dhaliwal J, Lagace DC. 2011. Visualization and genetic manipulation of adult neurogenesis using transgenic mice. Eur J Neurosci 33: 1025-1036.

Dieni CV, Chancey JH, Overstreet-Wadiche LS. 2012. Dynamic functions of GABA signaling during granule cell maturation. Front Neural Circuits 6: 113.

Dieni CV, Nietz AK, Panichi R, Wadiche JI, Overstreet-Wadiche L. 2013. Distinct determinants of sparse activation during granule cell maturation. J Neurosci 33: 1913119142.

Ding L, Saunders TL, Enikolopov G, Morrison SJ. 2012. Endothelial and perivascular cells maintain haematopoietic stem cells. Nature 481: 457-462.

Doetsch F, Caille I, Lim DA, Garcia-Verdugo JM, AlvarezBuylla A. 1999. Subventricular zone astrocytes are neural stem cells in the adult mammalian brain. Cell 97: 703 716.

Encinas JM, Enikolopov G. 2008. Identifying and quantitating neural stem and progenitor cells in the adult brain Methods Cell Biol 85: 243-272.

Encinas JM, Vaahtokari A, Enikolopov G. 2006. Fluoxetine targets early progenitor cells in the adult brain. Proc Natl Acad Sci 103: 8233-8238.

Encinas JM, Hamani C, Lozano AM, Enikolopov G. 2011a. Neurogenic hippocampal targets of deep brain stimulation. J Comp Neurol 519: 6-20.

Encinas JM, Michurina TV, Peunova N, Park JH, Tordo J, Peterson DA, Fishell G, Koulakov A, Enikolopov G. 2011b. Division-coupled astrocytic differentiation and age-related depletion of neural stem cells in the adult hippocampus. Cell Stem Cell 8: 566-579.

Filippov V, Kronenberg G, Pivneva T, Reuter K, Steiner B, Wang LP, Yamaguchi M, Kettenmann H, Kempermann G. 2003. Subpopulation of nestin-expressing progenitor cells in the adult murine hippocampus shows electrophysiological and morphological characteristics of astrocytes. Mol Cell Neurosci 23: 373-382.

Flesken-Nikitin A, Hwang CI, Cheng CY, Michurina TV, Enikolopov G, Nikitin AY. 2013. Ovarian surface epithelium at the junction area contains a cancer-prone stem cell niche. Nature 495: 241-245.

Fukuda S, Kato F, Tozuka Y, Yamaguchi M, Miyamoto Y, Hisatsune T. 2003. Two distinct subpopulations of nestin-positive cells in adult mouse dentate gyrus. J Neurosci 23: 9357-9366.

Ge S, Goh EL, Sailor KA, Kitabatake Y, Ming GL, Song H. 2006. GABA regulates synaptic integration of newly generated neurons in the adult brain. Nature 439: 589-593.

Ge S, Yang CH, Hsu KS, Ming GL, Song H. 2007. A critical period for enhanced synaptic plasticity in newly generated neurons of the adult brain. Neuron 54: 559-566.

Gleiberman AS, Encinas JM, Mignone JL, Michurina T, Rosenfeld MG, Enikolopov G. 2005. Expression of nestin-green fluorescent protein transgene marks oval cells in the adult liver. Dev Dyn 234: 413-421.

Gleiberman AS, Michurina T, Encinas JM, Roig JL, Krasnov P, Balordi F, Fishell G, Rosenfeld MG, Enikolopov G.
2008. Genetic approaches identify adult pituitary stem cells. Proc Natl Acad Sci 105: 6332-6337.

Imayoshi I, Sakamoto M, Kageyama R. 2011. Genetic methods to identify and manipulate newly born neurons in the adult brain. Front Neurosci 5: 64.

Jablonska B, Aguirre A, Raymond M, Szabo G, Kitabatake Y, Sailor KA, Ming GL, Song H, Gallo V. 2010. Chordininduced lineage plasticity of adult SVZ neuroblasts after demyelination. Nat Neurosci 13: 541-550.

Jang MH, Bonaguidi MA, Kitabatake Y, Sun J, Song J, Kang E, Jun H, Zhong C, Su Y, Guo JU, et al. 2013. Secreted frizzled-related protein 3 regulates activity-dependent adult hippocampal neurogenesis. Cell Stem Cell 12: 215-223.

Jensen P, Dymecki SM. 2014. Essentials of recombinasebased genetic fate mapping in mice. Methods Mol Biol 1092: 437-454.

Kawaguchi A, Miyata T, Sawamoto K, Takashita N, Murayama A, Akamatsu W, Ogawa M, Okabe M, Tano Y, Goldman SA, et al. 2001. Nestin-EGFP transgenic mice: Visualization of the self-renewal and multipotency of CNS stem cells. Mol Cell Neurosci 17: 259-273.

Kempermann G, Jessberger S, Steiner B, Kronenberg G. 2004. Milestones of neuronal development in the adult hippocampus. Trends Neurosci 27: 447-452.

Kim EJ, Ables JL, Dickel LK, Eisch AJ, Johnson JE. 2011. Ascl1 (Mash1) defines cells with long-term neurogenic potential in subgranular and subventricular zones in adult mouse brain. PLOS ONE 6: e18472.

Kronenberg G, Reuter K, Steiner B, Brandt MD, Jessberger S, Yamaguchi M, Kempermann G. 2003. Subpopulations of proliferating cells of the adult hippocampus respond differently to physiologic neurogenic stimuli. J Comp Neurol 467: 455-463.

* Kuhn HG, Eisch AJ, Spalding K, Peterson DA. 2015. Detection and phenotypic characterization of adult neurogenesis. Cold Spring Harb Perspect Biol doi: 10.1101/ cshperspect.a025981.

Kumamoto N, Gu Y, Wang J, Janoschka S, Takemaru K, Levine J, Ge S. 2012. A role for primary cilia in glutamatergic synaptic integration of adult-born neurons. Nat Neurosci 15: 399-405, S391.

Lagace DC, Whitman MC, Noonan MA, Ables JL, DeCarolis NA, Arguello AA, Donovan MH, Fischer SJ, Farnbauch LA, Beech R, et al. 2007. Dynamic contribution of nestinexpressing stem cells to adult neurogenesis. J Neurosci 27: $12623-12629$.

Liu X, Bolteus AJ, Balkin DM, Henschel O, Bordey A. 2006. GFAP-expressing cells in the postnatal subventricular zone display a unique glial phenotype intermediate between radial glia and astrocytes. Glia 54: 394-410.

Lugert S, Basak O, Knuckles P, Haussler U, Fabel K, Gotz M, Haas CA, Kempermann G, Taylor V, Giachino C. 2010. Quiescent and active hippocampal neural stem cells with distinct morphologies respond selectively to physiological and pathological stimuli and aging. Cell Stem Cell 6: $445-456$.

Markwardt SJ, Wadiche JI, Overstreet-Wadiche LS. 2009. Input-specific GABAergic signaling to newborn neurons in adult dentate gyrus. J Neurosci 29: 15063-15072. 
G. Enikolopov et al.

Markwardt SJ, Dieni CV, Wadiche JI, Overstreet-Wadiche L. 2011. Ivy/neurogliaform interneurons coordinate activity in the neurogenic niche. Nat Neurosci 14: 1407-1409.

McCarty DM, Young SM Jr, Samulski RJ. 2004. Integration of adeno-associated virus (AAV) and recombinant AAV vectors. Annu Rev Genet 38: 819-845.

McHugh TJ, Jones MW, Quinn JJ, Balthasar N, Coppari R, Elmquist JK, Lowell BB, Fanselow MS, Wilson MA, Tonegawa S. 2007. Dentate gyrus NMDA receptors mediate rapid pattern separation in the hippocampal network. Science 317: 94-99.

Mendez-Ferrer S, Michurina TV, Ferraro F, Mazloom AR, Macarthur BD, Lira SA, Scadden DT, Ma'ayan A, Enikolopov GN, Frenette PS. 2010. Mesenchymal and haematopoietic stem cells form a unique bone marrow niche. Nature 466: 829-834.

Merkle FT, Fuentealba LC, Sanders TA, Magno L, Kessaris N, Alvarez-Buylla A. 2014. Adult neural stem cells in distinct microdomains generate previously unknown interneuron types. Nat Neurosci 17: 207-214.

Mignone JL, Kukekov V, Chiang AS, Steindler D, Enikolopov G. 2004. Neural stem and progenitor cells in nestin-GFP transgenic mice. J Comp Neurol 469: 311-324.

Mignone JL, Roig-Lopez JL, Fedtsova N, Schones DE, Manganas LN, Maletic-Savatic M, Keyes WM, Mills AA, Gleiberman A, Zhang MQ, et al. 2007. Neural potential of a stem cell population in the hair follicle. Cell Cycle 6: 2161-2170.

Ming GL, Song H. 2011. Adult neurogenesis in the mammalian brain: Significant answers and significant questions. Neuron 70: 687-702.

Mitchell RS, Beitzel BF, Schroder AR, Shinn P, Chen H, Berry CC, Ecker JR, Bushman FD. 2004. Retroviral DNA integration: ASLV, HIV, and MLV show distinct target site preferences. PLoS Biol 2: E234.

Nacher J, Crespo C, McEwen BS. 2001. Doublecortin expression in the adult rat telencephalon. Eur J Neurosci 14: 629-644.

Nakashiba T, Cushman JD, Pelkey KA, Renaudineau S, Buhl DL, McHugh TJ, Rodriguez Barrera V, Chittajallu R, Iwamoto KS, McBain CJ, et al. 2012. Young dentate granule cells mediate pattern separation, whereas old granule cells facilitate pattern completion. Cell 149: 188-201.

Nolte C, Matyash M, Pivneva T, Schipke CG, Ohlemeyer C, Hanisch UK, Kirchhoff F, Kettenmann H. 2001. GFAP promoter-controlled EGFP-expressing transgenic mice: A tool to visualize astrocytes and astrogliosis in living brain tissue. Glia 33: 72-86.

Overstreet LS, Hentges ST, Bumaschny VF, de Souza FS, Smart JL, Santangelo AM, Low MJ, Westbrook GL, Rubinstein M. 2004. A transgenic marker for newly born granule cells in dentate gyrus. J Neurosci 24: 3251-3259.

Overstreet-Wadiche L, Bromberg DA, Bensen AL, Westbrook GL. 2005. GABAergic signaling to newborn neurons in dentate gyrus. J Neurophysiol 94: 4528-4532.

Overstreet-Wadiche LS, Bensen AL, Westbrook GL. 2006. Delayed development of adult-generated granule cells in dentate gyrus. J Neurosci 26: 2326-2334.

Park JH, Glass Z, Sayed K, Michurina TV, Lazutkin A, Mineyeva O, Velmeshev D, Ward WF, Richardson A, Enikolo- pov G. 2013. Calorie restriction alleviates the age-related decrease in neural progenitor cell division in the aging brain. Eur J Neurosci 37: 1987-1993.

Piatti VC, Davies-Sala MG, Esposito MS, Mongiat LA, Trinchero MF, Schinder AF. 2011. The timing for neuronal maturation in the adult hippocampus is modulated by local network activity. J Neurosci 31: 7715-7728.

Sandler R, Smith AD. 1991. Coexistence of GABA and glutamate in mossy fiber terminals of the primate hippocampus: An ultrastructural study. J Comp Neurol 303: 177-192.

Seri B, Garcia-Verdugo JM, Collado-Morente L, McEwen BS, Alvarez-Buylla A. 2004. Cell types, lineage, and architecture of the germinal zone in the adult dentate gyrus. J Comp Neurol 478: 359-378.

Shcherbakova DM, Sengupta P, Lippincott-Schwartz J, Verkhusha VV. 2014. Photocontrollable fluorescent proteins for superresolution imaging. Annu Rev Biophys 43: 303-329.

Sloviter RS, Dichter MA, Rachinsky TL, Dean E, Goodman JH, Sollas AL, Martin DL. 1996. Basal expression and induction of glutamate decarboxylase and GABA in excitatory granule cells of the rat and monkey hippocampal dentate gyrus. J Comp Neurol 373: 593-618.

Smith RH. 2008. Adeno-associated virus integration: Virus versus vector. Gene Ther 15: 817-822.

Snyder JS, Ferrante SC, Cameron HA. 2012. Late maturation of adult-born neurons in the temporal dentate gyrus. PLOS ONE 7: e48757.

Song J, Zhong C, Bonaguidi MA, Sun GJ, Hsu D, Gu Y, Meletis K, Huang ZJ, Ge S, Enikolopov G, et al. 2012. Neuronal circuitry mechanism regulating adult quiescent neural stem-cell fate decision. Nature 489: 150-154.

Song J, Sun J, Moss J, Wen Z, Sun GJ, Hsu D, Zhong C, Davoudi H, Christian KM, Toni N, et al. 2013. Parvalbumin interneurons mediate neuronal circuitry-neurogenesis coupling in the adult hippocampus. Nat Neurosci 16: $1728-1730$.

Spampanato J, Sullivan RK, Turpin FR, Bartlett PF, Sah P. 2012. Properties of doublecortin expressing neurons in the adult mouse dentate gyrus. PLoS ONE 7: e41029.

Steiner B, Klempin F, Wang L, Kott M, Kettenmann H, Kempermann G. 2006. Type-2 cells as link between glial and neuronal lineage in adult hippocampal neurogenesis. Glia 54: 805-814.

Suh H, Consiglio A, Ray J, Sawai T, D’Amour KA, Gage FH. 2007. In vivo fate analysis reveals the multipotent and self-renewal capacities of Sox2 ${ }^{+}$neural stem cells in the adult hippocampus. Cell Stem Cell 1: 515-528.

Sun MY, Yetman MJ, Lee TC, Chen Y, Jankowsky JL. 2014. Specificity and efficiency of reporter expression in adult neural progenitors vary substantially among nestinCreER $^{\mathrm{T} 2}$ lines. J Comp Neurol 522: 1191-1208.

Thomas CE, Ehrhardt A, Kay MA. 2003. Progress and problems with the use of viral vectors for gene therapy. Nat Rev Genet 4: 346-358.

Tozuka Y, Fukuda S, Namba T, Seki T, Hisatsune T. 2005. GABAergic excitation promotes neuronal differentiation in adult hippocampal progenitor cells. Neuron 47: $803-815$. 
Uchigashima M, Fukaya M, Watanabe M, Kamiya H. 2007. Evidence against GABA release from glutamatergic mossy fiber terminals in the developing hippocampus. J Neurosci 27: 8088-8100.

Wang LP, Kempermann G, Kettenmann H. 2005. A subpopulation of precursor cells in the mouse dentate gyrus receives synaptic GABAergic input. Mol Cell Neurosci 29: $181-189$.

Yamaguchi M, Saito H, Suzuki M, Mori K. 2000. Visualization of neurogenesis in the central nervous system using nestin promoter-GFP transgenic mice. Neuroreport 11: 1991-1996.

Yang Z, Ming GL, Song H. 2011. Genetically targeting new neurons in the adult hippocampus. Cell Res 21:220-222.
Zhang J, Giesert F, Kloos K, Vogt Weisenhorn DM, Aigner L, Wurst W, Couillard-Despres S. 2010. A powerful transgenic tool for fate mapping and functional analysis of newly generated neurons. BMC Neurosci 11: 158 .

Zhao S, Zhou Y, Gross J, Miao P, Qiu L, Wang D, Chen Q, Feng G. 2010. Fluorescent labeling of newborn dentate granule cells in GAD67-GFP transgenic mice: A genetic tool for the study of adult neurogenesis. PLoS ONE 5: e122506.

Zimmerman L, Parr B, Lendahl U, Cunningham M, McKay R, Gavin B, Mann J, Vassileva G, McMahon A. 1994. Independent regulatory elements in the nestin gene direct transgene expression to neural stem cells or muscle precursors. Neuron 12: 11-24. 


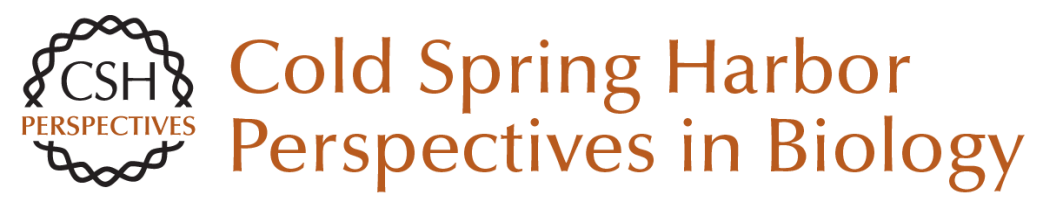

\section{Viral and Transgenic Reporters and Genetic Analysis of Adult Neurogenesis}

Grigori Enikolopov, Linda Overstreet-Wadiche and Shaoyu Ge

Cold Spring Harb Perspect Biol 2015; doi: 10.1101/cshperspect.a018804

\section{Subject Collection Neurogenesis}

Adult Neurogenesis and Psychiatric Disorders

Eunchai Kang, Zhexing Wen, Hongjun Song, et al.

Neuronal Circuitry Mechanisms Regulating Adult

Mammalian Neurogenesis Juan Song, Reid H.J. Olsen, Jiaqi Sun, et al.

Neurogenesis in the Developing and Adult Brain

--Similarities and Key Differences

Magdalena Götz, Masato Nakafuku and David Petrik

Genetics and Epigenetics in Adult Neurogenesis Jenny Hsieh and Xinyu Zhao

The Adult Ventricular-Subventricular Zone (V-SVZ) and Olfactory Bulb (OB) Neurogenesis Daniel A. Lim and Arturo Alvarez-Buylla

Diversity of Neural Precursors in the Adult Mammalian Brain

Michael A. Bonaguidi, Ryan P. Stadel, Daniel A. Berg, et al.

Detection and Phenotypic Characterization of Adult Neurogenesis H. Georg Kuhn, Amelia J. Eisch, Kirsty Spalding, et al.

Maturation and Functional Integration of New Granule Cells into the Adult Hippocampus Nicolas Toni and Alejandro F. Schinder
Adult Olfactory Bulb Neurogenesis

Pierre-Marie Lledo and Matt Valley

Adult Neurogenesis in Fish Julia Ganz and Michael Brand

In Vitro Models for Neurogenesis Hassan Azari and Brent A. Reynolds

\section{Engineering of Adult Neurogenesis and Gliogenesis \\ Benedikt Berninger and Sebastian Jessberger \\ Computational Modeling of Adult Neurogenesis James B. Aimone \\ Control of Adult Neurogenesis by Short-Range Morphogenic-Signaling Molecules Youngshik Choe, Samuel J. Pleasure and Helena Mira}

Adult Neurogenesis: An Evolutionary Perspective Gerd Kempermann

Epilepsy and Adult Neurogenesis Sebastian Jessberger and Jack M. Parent

For additional articles in this collection, see http://cshperspectives.cshlp.org/cgi/collection/

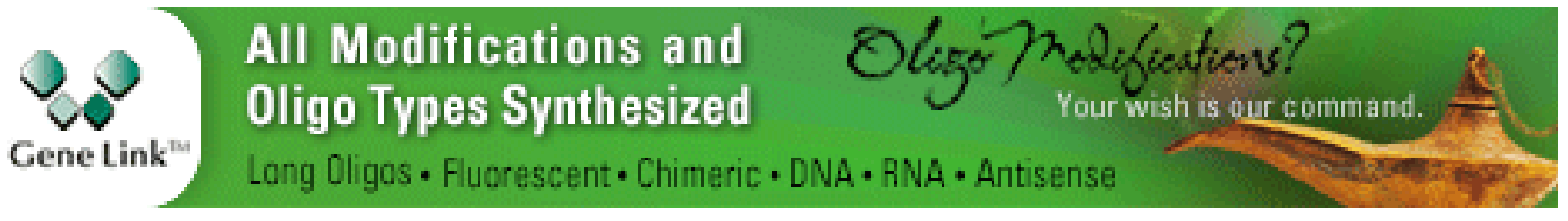


For additional articles in this collection, see http://cshperspectives.cshlp.org/cgi/collection/

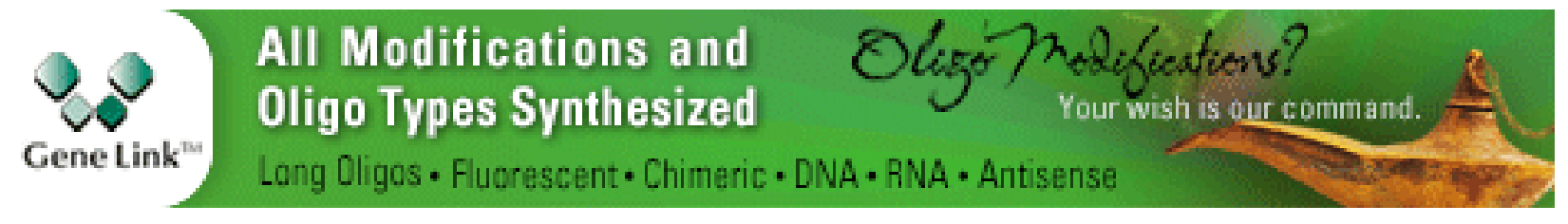

Copyright @ 2015 Cold Spring Harbor Laboratory Press; all rights reserved 